\title{
Global-Scale Comparison of MISR and MODIS Land Surface Albedos
}

\author{
BERNARD PINTY \\ Earth Observation Directorate, ESA-ESRIN, Frascati, and European Commission, DG Joint Research Centre, \\ Institute for Environment and Sustainability, Global Environment Monitoring Unit, Ispra, Italy \\ MALCOLM TABERNER \\ The Remote Sensing Group, Plymouth Marine Laboratory, Plymouth, United Kingdom \\ VANCE R. HAEMmerle AND SUSAn R. PARAdise \\ Jet Propulsion Laboratory, Pasadena, California \\ ERIC VERMOTE \\ Department of Geography, University of Maryland, College Park, College Park, and NASA GSFC, Greenbelt, Maryland \\ Michel M. Verstraete, Nadine Gobron, and Jean-Luc Widlowski \\ European Commission, DG Joint Research Centre, Institute for Environment and Sustainability, Global Environment \\ Monitoring Unit, Ispra, Italy
}

(Manuscript received 5 March 2010, in final form 29 September 2010)

\begin{abstract}
The Moderate Resolution Imaging Spectroradiometer (MODIS) white-sky surface albedos are compared with similar products generated on the basis of the Multiangle Imaging SpectroRadiometer (MISR) surface bidirectional reflectance factor (BRF) model parameters available for the year 2005. The analysis is achieved using global-scale statistics to characterize the broad patterns of these two independent albedo datasets. The results obtained in $\mathrm{M}$. Taberner et al. have shown that robust statistics can be established and that both datasets are highly correlated. As a result, the slight but consistent biases and trends identified in this paper, derived from statistics obtained on a global basis, should be considered sufficiently reliable to merit further investigation. The present paper reports on the zonal- and seasonal-mean differences retrieved from the analysis of the MODIS and MISR surface albedo broadband products. The MISR - MODIS differences exhibit a systematic positive bias or offset in the range of $0.01-0.03$ depending on the spectral domain of interest. Results obtained in the visible domain exhibit a well-marked and very consistent meridional trend featuring a "smile effect" such that the MISR - MODIS differences reach maxima at the highest latitudes in both hemispheres. The analysis of seasonal variations observed in MISR and MODIS albedo products reveals that, in the visible domain, the MODIS albedos generate weaker seasonal changes than MISR and that the differences increase poleward from the equatorial regions. A detailed investigation of MODIS and MISR aerosol optical depth retrievals suggests that this large-scale meridional trend is probably not caused by differences in the aerosol load estimated by each instrument. The scale and regularity of the meridional trend suggests that this may be due to the particular sampling regime of each instrument in the viewing azimuthal planes and/or approximations in the atmospheric correction processes. If this is the case, then either MODIS is underestimating, or MISR overestimating, the surface anisotropy or both.
\end{abstract}

Corresponding author address: Bernard Pinty, European Commission, DG Joint Research Centre, Institute for Environment and Sustainability, Global Environment Monitoring Unit, TP 272, via Enrico Fermi 2749, I-21027 Ispra (VA), Italy.

E-mail: bernard.pinty@jrc.ec.europa.eu

\section{Introduction}

The albedo, representing the fraction of backscattered solar radiant flux at any relevant level, is used to evaluate the distribution of solar energy between various components of the geophysical systems and in particular 
the fractions absorbed in the atmosphere, vegetation, and soil layers. When estimated at the level of the surface, this quantity provides a lower-boundary condition for the atmosphere (itself related to latent and sensible heat fluxes in the atmospheric boundary layer) and an upper-boundary condition for the vegetation systems. Surface albedo thus plays a critical role in partitioning the solar radiant flux absorbed in the vegetation and soil layers (e.g., Pinty et al. 2008), which drives processes such as evaporation and photosynthesis in the canopy and water and heat transfer in the underlying soil (e.g., Dickinson 1983; Avissar and Verstraete 1990; Sellers et al. 1997; Viterbo and Betts 1999).

Albedo may also significantly contribute to weather and climate studies: the assimilation of such products will add relevant constraints to the land surfaces processes that are still crudely parameterized in these large-scale models. Meteorologists traditionally tend to assimilate radiance observations rather than the geophysical products derived from these radiances whenever possible. In the case of land surface processes, this question becomes more acute because of the importance of three-dimensional effects driving the radiation regimes in vegetation canopies, especially over forested regions (e.g., Betts et al. 2007). The most advanced representation of radiation transfer processes over land surfaces in large-scale models is, however, confined to onedimensional approaches. This leads to some significant inconsistencies and biased results when assimilating, for instance, advanced surface products such as the leaf area index (LAI) if this retrieval accounts for the three-dimensional and associated tree-clumping effects (Pinty et al. 2006, section 2.3).

It is unlikely that the representation of realistic threedimensional features in large-scale models will improve at a speed comparable to the delivery and validation of surface products such as albedo, although some interesting initiatives are emerging (Dickinson et al. 2008). In the meantime, the radiation transfer-modeling tools needed to interface large-scale models with albedo values derived from space measurements have become available (e.g., Pinty et al. 2006). By the same token, the capability of using these albedos as an input to inverse schemes for partitioning the solar radiant flux absorbed in the vegetation and soil components have been demonstrated (e.g., Pinty et al. 2007; Liu et al. 2008). In a sense, albedo quantities are the closest products to the native scattered radiance fields measured by satellites at the top of the atmosphere, and they represent an intermediary step between the assimilation of measured radiances (a rather complex task) and higher-level surface products such as LAI (which may be sources of biases and inconsistencies).
Surface albedo estimates result from a series of radiation transfer processes involving the joint interactions between atmospheric and surface layers. The joint radiation transfer regimes that are established in both layers generally result from rather complex processes, in particular as a result of the angular dependency of the radiation scattered by the surface, which can be strongly controlled by three-dimensional effects intrinsic to the vegetation layers (e.g., Pinty et al. 2005). To satisfy a number of atmospheric-modeling and surface-monitoring applications, it is useful to focus on two extreme albedo quantities-namely, a directional hemispherical reflectance (DHR) called black-sky albedo associated with direct illumination only, and a bihemispherical reflectance $\left(\mathrm{BHR}_{\text {iso }}\right)$ called white-sky albedo associated with a purely isotropic field of downwelling radiances. These two albedo quantities, when defined at the top of the canopy level, are thus intrinsic surface properties (no contamination by rapidly changing atmospheric ambient conditions) that can be further linearly combined to approximate the actual surface albedo (using the fraction of diffuse downwelling radiation as a weighting factor; e.g., Kondratyev 1972; Lewis and Barnsley 1994; Pinty et al. 2005; Román et al. 2010).

The retrieval of the surface albedo values from spaceborne sensors is hindered by the surface-atmosphere radiation transfer coupling, and it is only recently that improved inverse algorithms and advanced space technology-for instance, as available from the Moderate Resolution Imaging Spectroradiometer (MODIS) and the Multiangle Imaging SpectroRadiometer (MISR) sensors-have allowed us to generate high-resolution albedo quantities with the required accuracy and precision at the global scale and over multiple consecutive years. The methodology adopted to generate comparable albedo quantities from both sensors has been presented in Taberner et al. (2010). The two sets of surface albedo products are highly correlated despite a few issues related to differences in the spatial, temporal, angular, and spectral domain sampling schemes. This encouraging finding was established from an analysis of white-sky albedo datasets derived for the year 2005 in three broadband spectral domains of interest, namely the visible (0.3$0.7 \mu \mathrm{m})$, the near infrared $(0.7-3.0 \mu \mathrm{m})$, and the shortwave $(0.3-3.0 \mu \mathrm{m})$.

The rather good statistical agreement between the two albedo datasets supports a more in-depth investigation to evaluate the potential biases and trends that may exist at global and seasonal scales. This paper aims to document the deviations observed between the two datasets on the basis of zonally and seasonally averaged values under snow-free conditions. This investigation is based on the most integrated (in the angular and spectral 
dimensions) set of products available at the global scale to build robust statistics and to limit the contributions from local features. The results obtained are analyzed in the light of analogous statistics derived from the atmospheric aerosol products and other elements of the algorithms applied to the MODIS and MISR measurements that contribute to the retrieval of surface albedos.

\section{Zonal and seasonal means}

\section{a. Datasets}

The MISR dataset has been derived from the land surface BRF model parameters following the angular integration and spectral conversion schemes outlined in sections 2.1 and 2.2 of Taberner et al. (2010), respectively. The MODIS dataset consists of "high-quality" white-sky albedos, as identified by the associated MODIS quality flag, coincidental with MISR 1-km products. Most of the results shown here are based on the MODIS 1-km spatial resolution product (from MCD43B) following the processing described in detail from Taberner et al. (2010) unless otherwise stated. The MODIS 1-km surface albedo products result from an averaging of the underlying 500-m-resolution retrievals (from MCD43A). The quality flags associated with the $1-\mathrm{km}$ product identify the status of the majority of the 500-m quality flags. To assess the actual impact of this filtering regime on the results discussed in this contribution (C. Schaaf 2010, personal communication), the relationship between the 500-m and 1-km MODIS datasets was examined; seasonal and zonal statistics were produced using both the 1-km- and 500-m-resolution datasets (and associated flags). No significant differences were found in the zonal and seasonal means, even with the most conservative filtering, suggesting that there is no discernible zonally consistent cloud and/or snow subpixel contamination of the high-quality 1-km MODIS broadband products.

The natural distribution and variability of climate and vegetation over land suggests the evaluation of trends and biases on the basis of zonal (due to the repartition of land cover type with latitude) and seasonal (most vegetated surfaces exhibit a phenological cycle) means. The polar regions are excluded from the present investigation, and the land areas of concern here are mostly located between latitudes $50^{\circ} \mathrm{S}$ and $70^{\circ} \mathrm{N}$. The seasons are simply referred to with respect to the Northern Hemisphere: the summer (winter) season is defined as between 8 April and 30 September (1 October and 7 April). For the purpose of this study, the summer (winter) season is associated with the period of the most vigorous growth and development (senescence and dormancy) activity for the dominant ecosystems at mid and high latitudes. Vegetation phenology is indeed largely consistent on a continental scale, and this broad pattern is clearly noticeable in zonal analyses of MODIS surface products as shown in Zhang et al. (2006, see their Figs. 6 and 7), Gao et al. (2005, see their Fig. 5), and Moody et al. (2008, see their Fig. 9), for example. The winter means are calculated by grouping together geophysical values available for the beginning and the end of the year 2005. The zonally and seasonally averaged quantities are calculated on the basis of the $0.01^{\circ}$ resolution products over all land areas (without weighing by the surface area) defined at this resolution. A dedicated land mask has been created based on the yearly accumulation of the 16-day-period MODIS surface product flagged as "land."

It is important to document the temporal- and spatialsampling differences between the MISR and MODIS datasets when evaluating the statistical significance of differences in zonal and seasonal averages. Figure $1 \mathrm{ex}$ hibits the sampling efficiency of MODIS (top panel) and MISR (middle panel) over all land areas over the globe for the year 2005. The sampling efficiency is defined as the number of surface albedo values actually available (high-quality valid retrievals only), normalized by the maximum number that could ideally be reached within a 16-day-period sequential accumulation. The sampling efficiencies of MODIS and MISR are broadly similar. Both exhibit large spatiotemporal gradients with a wellmarked signature of the cloudy intertropical convergence zone around the equator and quite symmetrical patterns with respect to the months of June-July. MISR shows an increased sampling efficiency at latitudes higher than $40^{\circ}$ in the winter season, that is, mostly related to the occurrence of snow events. By contrast, the sampling efficiency offered by MODIS is slightly better than that of MISR in the $10^{\circ}-40^{\circ}$ latitude bands in both hemispheres and much better at latitudes higher than $50^{\circ}$ during the summer season in the Northern Hemisphere.

The latitudinal variation of the absolute number of common samples between MODIS and MISR is shown in the bottom panel of Fig. 1, when only snow-free conditions as reported by the MODIS snow flag are considered. The obscuration of land surfaces by clouds associated with the intertropical convergence zone and its latitudinal shift with the seasons is perceptible around the equatorial region. The differences between the winter and summer season values in the Northern Hemisphere are due to extensive seasonal snow cover. This effect is dampened in the Southern Hemisphere because of the limited land area subject to snow occurrence. The reduction in the number of samples around the equatorial regions and at high latitudes (poleward 


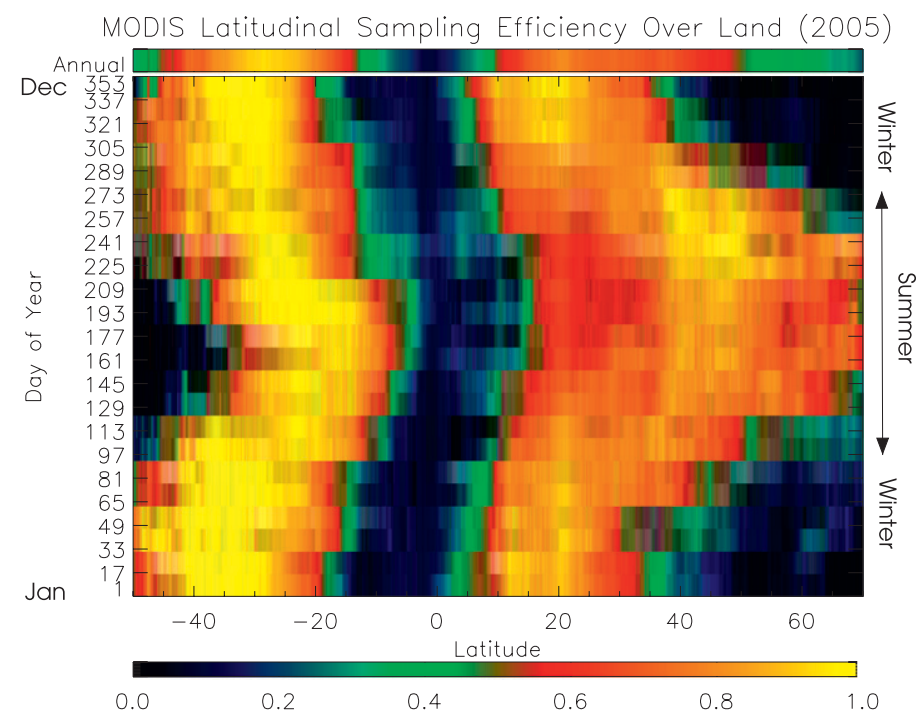

MISR Latitudinal Sampling Efficiency Over Land (2005)
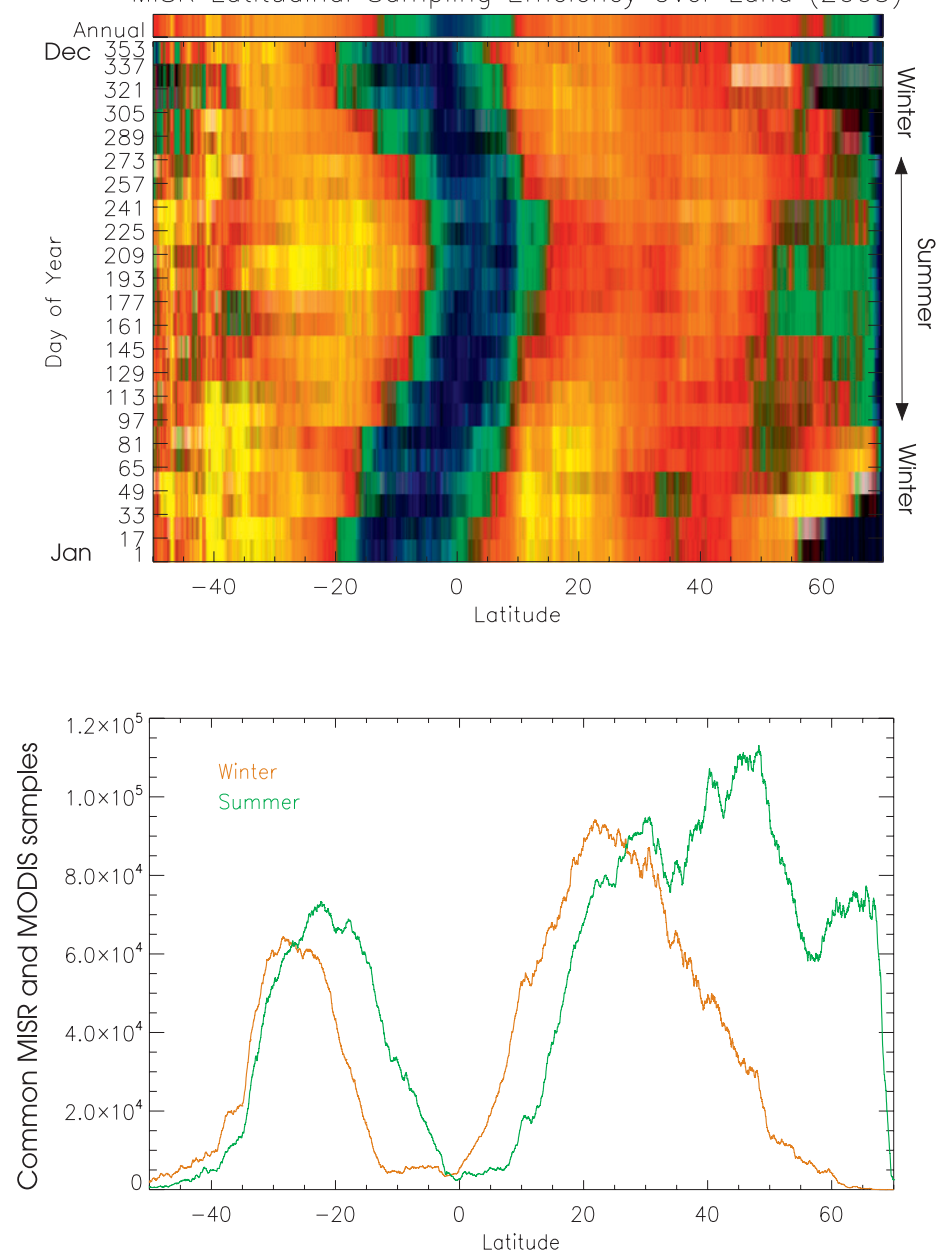

FIG. 1. Sampling efficiency of (top) MODIS and (middle) MISR over land areas for the year 2005. The sampling efficiency is defined as the number of actual surface albedo products (high-quality valid retrievals) normalized by the maximum number that could be reached with a 16-day-period sequential accumulation. (bottom) The number of common MODIS and MISR samples under snow-free conditions only. 
of $60^{\circ} \mathrm{N}$ and $40^{\circ} \mathrm{S}$ ) during the winter seasons will translate into a reduced robustness of the zonal-mean statistics over the concerned regions. This situation seriously limits the possibility of reliably assessing the large-scale albedo differences at higher temporal resolutions than the two seasons considered here.

\section{b. Results}

The most prominent results of the current investigation are summarized in Fig. 2. These panels display, as a function of latitude and at a resolution of $0.01^{\circ}$, the MISR - MODIS absolute differences between the snow-free zonal means calculated for the winter and summer seasons for the year 2005, respectively. Note that the MISR - MODIS absolute differences have been calculated first for each land grid cell where both MISR and MODIS high-quality 1-km retrievals were available over each 16-day period and then aggregated over longitudes and seasons, as appropriate. The same procedure was applied to the 500-m-resolution MODIS albedo product except the most conservative filtering scheme was used where the aggregation at $1 \mathrm{~km}$ represents the average of all high-quality snow-free pixels falling in the MISR 1-km footprint and including those cases where only one (out of four) single 500-m MODIS pixel met these conditions. As mentioned previously, similar patterns are seen in both the 1-km- and 500-m-resolution products. The MODIS snow indicator has been used to screen out snow conditions in both the MODIS and MISR datasets. In addition, outliers that may be caused by ephemeral snow events as illustrated in Fig. 11 of Taberner et al. (2010) have been removed following the procedure described in that paper's section 2.3. The most noticeable features are 1) the presence of biases, with MISR values being systematically larger than the corresponding MODIS values in all three broadbands, and 2) the latitudinal trends that are particularly consistent in the visible domain in both seasons.

The differences between these two datasets, on the order of $0.01-0.03$, are small and depend somewhat on the spectral domain. Nevertheless, because they represent an average bias or offset for millions of data points, they are considered significant enough to require further investigation. It is noteworthy that the sign and order of magnitude of these biases fall well within the range of results obtained in the visible part of the spectrum from detailed analysis of MISR - MODIS calibration differences using in situ aerosol measurements (see Lyapustin et al. 2007). In the near-infrared part of the spectrum, such MISR - MODIS biases are probably within the expected range, given the uncertainty associated with the narrow to broadband conversion due to the limited sampling of this domain by MISR.
A "smile effect," characterizing the meridional trends between both albedo datasets is affecting all three broadband zonal profiles and is particularly apparent in the visible domain. A very consistent seasonal variation is observed on this trend such that the highest deviations occur under the highest sun zenith angle conditions; that is, differences are higher in the winter seasons of a given hemisphere. In the near-infrared domain, this seasonal variation of the trend is mostly affecting the Southern Hemisphere. The large variability in the trends that is evidenced at the highest latitudes is a direct consequence of the limited sampling of snowfree land surfaces over these regions.

These trends are altering the estimates of the amplitude of the seasonal variations depicted by the zonal means of the albedo values. Figure 3 displays the 6month-period seasonal variations (northern summer northern winter) inferred from MODIS (in red) and MISR (in blue) in the three spectral broadbands. Before delving into the detailed interpretation of this figure, it is appropriate to highlight the expected behavior of the seasonal changes as a function of latitude. In short, the growing phase of vegetation is associated with a relative increase in the near-infrared surface albedo values (because of the enhanced probability of scattering by the leaves relative to the underlying soil) and a decrease in the visible surface albedo values (because of the enhanced probability of absorption by chlorophyll contained in the leaves). The opposite situation occurs during the senescence phase since leaf density decreases and larger fractions of soils contribute to the scattering processes. This is clearly seen in surface albedo time series that cover a full vegetation cycle (see Fig. 5 in Pinty et al. 2007 and Fig. 9 in Moody et al. 2008). Accordingly, using the Northern Hemisphere as the reference for defining the seasons, one should expect that the summer - winter differences tend to be positive (negative) in the near-infrared (visible) domain over the mid- and high-latitude regions of the Northern Hemisphere, that is, typically regions located north of the $30^{\circ}-35^{\circ} \mathrm{N}$ latitude band. Based on the same reasoning, the summer - winter differences should yield negative (positive) values in the near-infrared (visible) over the Southern Hemisphere, that is, those regions south of the $20^{\circ}-25^{\circ} \mathrm{N}$ latitude band.

It must be recalled that regional effects can override this global pattern, especially for intertropical regions. For instance, fire disturbances tend to darken land surfaces, sometimes over large areas (e.g., Pinty et al. 2000), while monsoon regimes drive the vegetation phenology in subtropical regions and may shift the onset of the growing and senescence periods relative to mid- and 

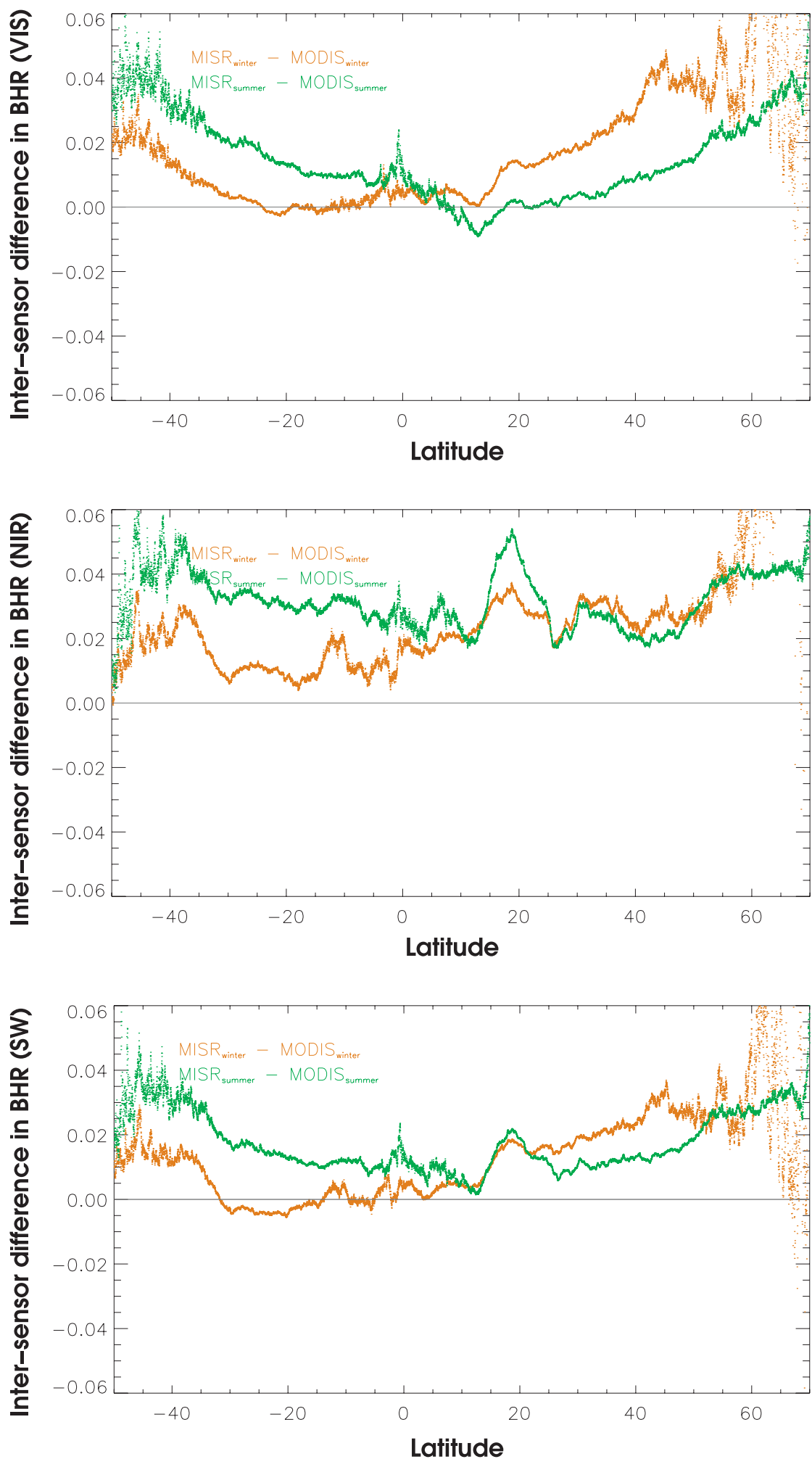

FIG. 2. MISR - MODIS surface albedo absolute differences of the zonal means at $0.01^{\circ}$ resolution calculated for the winter (brown) and summer (green) seasons of the year 2005 for snow-free conditions. The snow conditions are screened using the MODIS snow flag in both datasets. High-quality MODIS products only are considered. The broadband (top) visible, (middle) near-infrared, and (bottom) shortwave spectral domains are shown. 

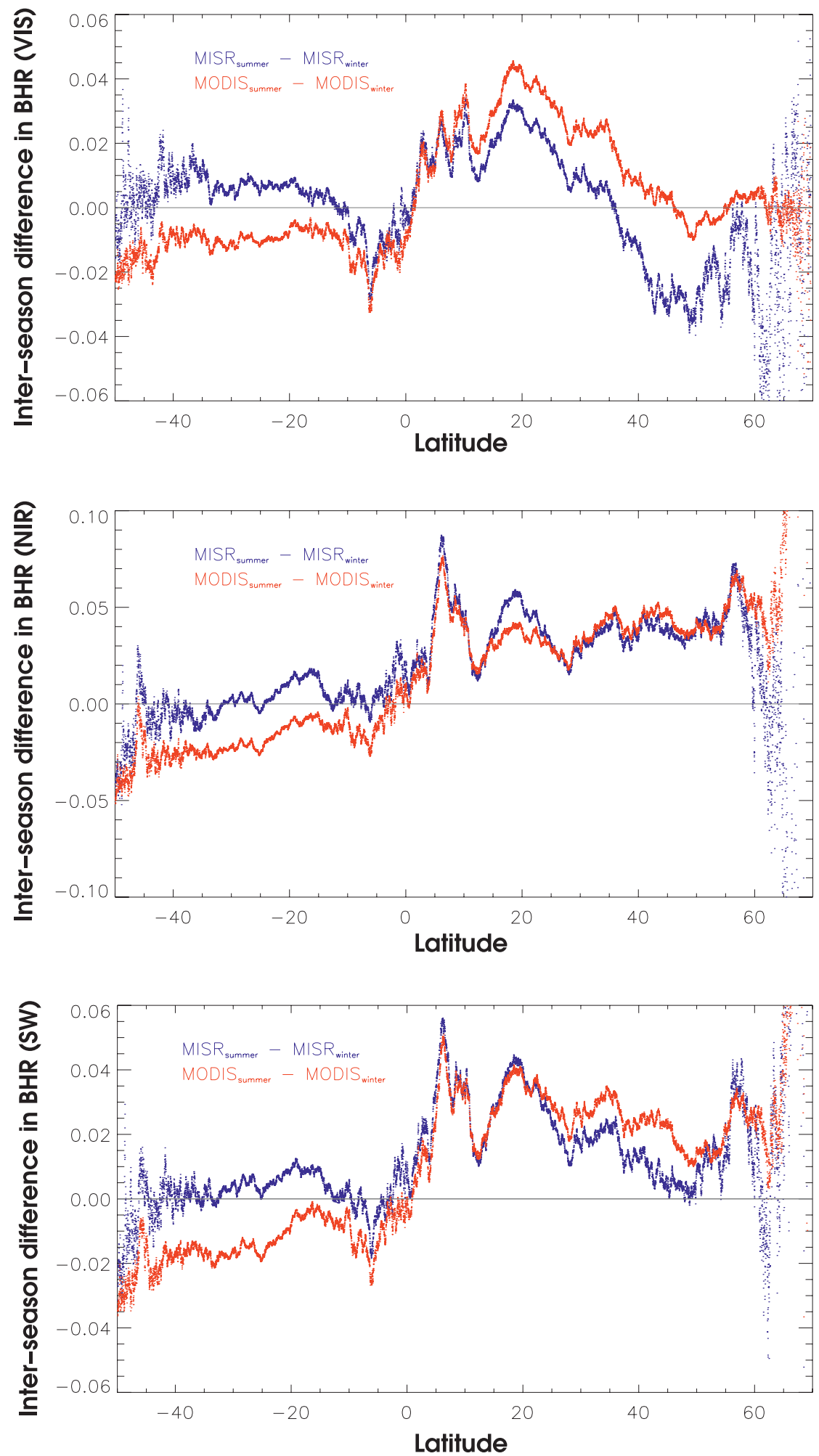

FIG. 3. Seasonal variations (northern summer - northern winter) estimated for the year 2005 from the MISR (blue) and MODIS (red) zonal-averaged surface albedo values. The MODIS snow indicator has been used to screen out the snow conditions in both the MODIS and MISR datasets. High-quality MODIS products only are considered. The broadband (top) visible, (middle) near-infrared, and (bottom) shortwave spectral domains are shown. 
high-latitude vegetation. Other subtle effects can modify further the zonal analysis, such as the presence of desertic and evergreen land areas, which weaken the amplitude of the seasonal variations due, for instance, to the croplands and deciduous broadleaf forests. Also, in contrast to the Northern Hemisphere, the statistics accumulated beyond $40^{\circ} \mathrm{S}$ are less reliable owing to the relatively limited extent of the vegetated land areas.

Figure 3 shows that the seasonal variations observed in the near-infrared domain (middle panel) by both MODIS and MISR datasets agree quite well with the broad phenological patterns outlined above, with negative and positive values (of the summer - winter seasonal differences) in mid- and high-latitude regions in the Southern and Northern Hemisphere, respectively. Both sets of products also reproduce the rather sharp gradients observed around the equatorial regions despite the reduced sampling in this zone due to the intense cloudiness as illustrated in Fig. 1. The MODIS and MISR datasets generate very similar variations in the Northern Hemisphere, whereas MODIS values suggest a stronger seasonal change than MISR does in the near-infrared domain in the Southern Hemisphere. The scattered points poleward of $60^{\circ}$ latitude, mainly distributed in the negative (positive) part of the panels in the Northern (Southern) Hemisphere, are probably due to the presence of some unscreened MISR pixels partially contaminated by snow occurring in these subsampled regions.

The situation is more contrasted in the visible domain (top panel in Fig. 3) since MODIS and MISR datasets show significant differences regarding the meridional trend, particularly at mid and high latitudes. With the MISR dataset, the seasonal variations show mostly positive and negative values (of the summer - winter season difference) for the Southern and Northern Hemispheres, respectively, which agrees with the broadly expected patterns relating to vegetation phenology at these latitudes. With MODIS, on the other hand, the seasonal variations are characterized by almost always positive (negative) and close to zero values in the Northern (Southern) Hemisphere. As a result, MODIS visible albedos exhibit a weaker seasonal change than suggested by MISR.

Regions located between $30^{\circ}$ and $60^{\circ} \mathrm{N}$ are of particular interest here since the fraction occupied by land areas is large enough to establish robust zonal and seasonal statistics and the contribution from the type of vegetation that follows the broad phenological patterns discussed previously (e.g., managed croplands and deciduous broadleaf and needleleaf forests) is expected to be significant (Bartholomé and Belward 2005). Figure 4 displays the seasonal- and zonal-mean absolute values in white-sky albedos based on the 500-m-resolution MODIS products and calculated using the 1-km aggregation and screening procedures described in section 2a. The top and middle panels correspond to the MODIS broadband near-infrared and visible albedos, respectively, and the bottom panel refers to the corresponding mean MISR broadband visible albedo values estimated in the $30^{\circ}$ and $60^{\circ} \mathrm{N}$ latitude band. The mean MISR broadband nearinfrared values are not shown here as they follow very closely those estimated from MODIS (see middle panel in Fig. 3). It thus appears that the MISR dataset follows the temporal change in the zonal means that would be expected in the mid- and high-latitude regions, given the background information about vegetation phenology discussed previously. By comparison, the seasonal variations depicted by the MODIS dataset are weaker and, although the absolute values of the differences remain small, this disagreement may impact some downstream surface applications.

The presence (as suggested by the MISR dataset) or lack (as suggested by the MODIS dataset) of coincidental albedo changes in both the near-infrared and visible domains has indeed some implications regarding the domain-averaged scattering properties of the vegetation canopy layer and/or the background soil below vegetation as already observed by Pinty et al. (2007, 2008). One indeed has to consider, for instance, the occurrence of relatively dark background soil conditions to reconcile changes in LAI, as commonly associated with vegetation phenological cycles, that are not mirrored by significant modifications in the visible albedos but induce variations in the near-infrared albedos (Pinty et al. 2009, see their Figs. 5 and 6).

\section{Discussion of the MISR - MODIS differences}

The results of the statistical analyses of MISR - MODIS surface albedo differences have revealed the presence of small but systematic biases or offsets in all three broadbands, with MISR values consistently exceeding those from MODIS. The orders of magnitude of these biases remain in the expected range estimated from detailed local investigations in the visible domain. In the nearinfrared broadband domain, the limited and biased spectral sampling from MISR hardly permits us to investigate this problem further, given the uncertainties associated with the spectral conversion.

The meridional trends exposed-as well characterized by a smile effect in the visible domain-require more in-depth analysis given their impact on the global-scale vegetation properties at mid and high latitudes (where the relative differences in zonal-mean albedos culminate at $25 \%-30 \%$ in relative units). The visible domain does not suffer from spectral sampling limitations in the MODIS and MISR datasets; that is, 

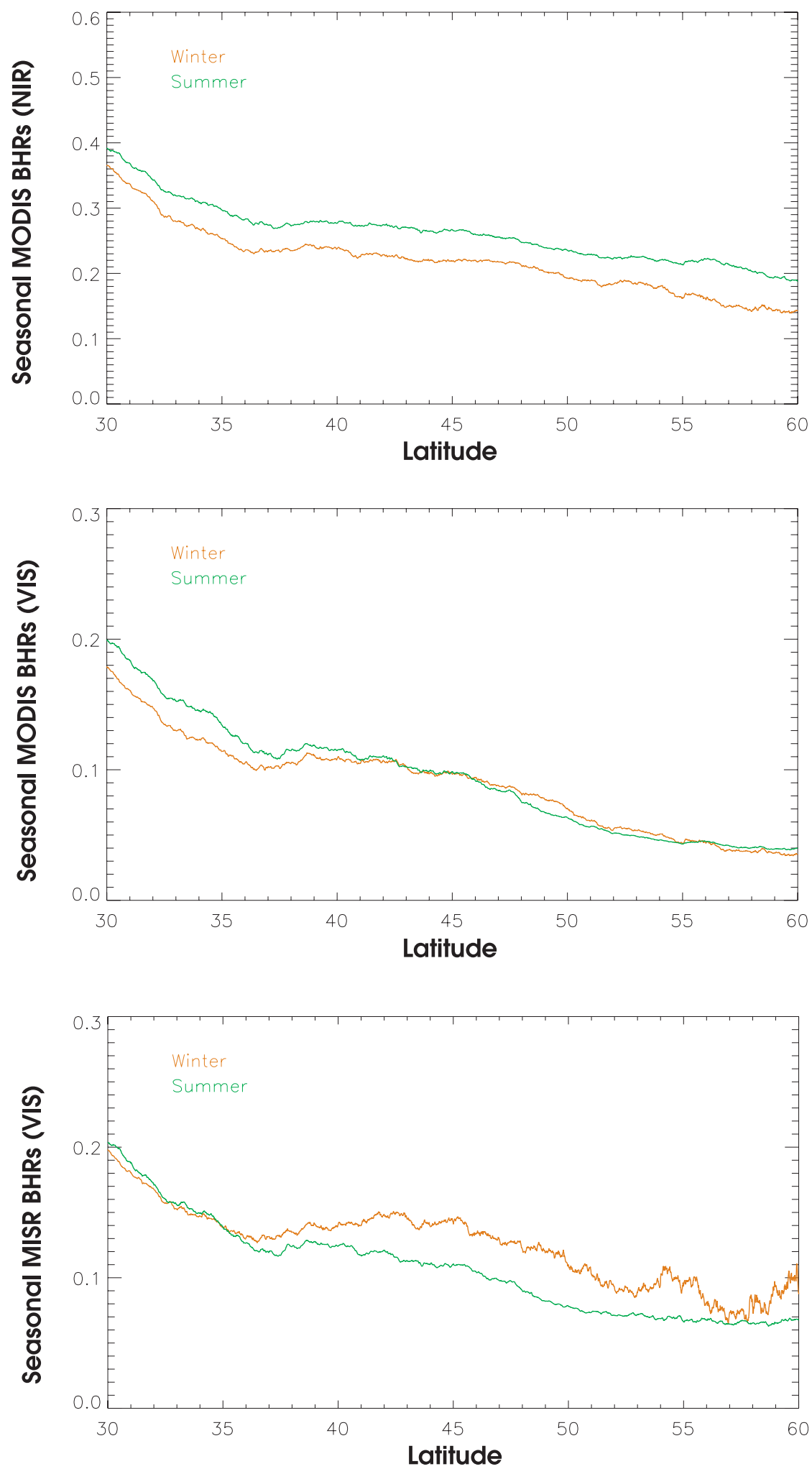

FIG. 4. Zonal means of the absolute values in white-sky albedos in northern summer (green) and winter (brown) based on the 500-m-resolution MODIS products and calculated using the 1-km aggregation and screening procedures described in section 2a. The MODIS broadband (top) near-infrared and (middle) visible albedos and (bottom) the corresponding mean MISR broadband visible albedo values estimated in the $30^{\circ}$ and $60^{\circ} \mathrm{N}$ latitude band are shown. 
the spectral conversion is simply acting as a spectralaveraging procedure, which should not add much uncertainty to the broadband-derived products.

In the following, we focus on two possible causes for the observed discrepancies in the visible domain: the contribution related to the aerosol load estimates and the role of land surface anisotropy, which is particularly relevant at short wavelengths where strong absorption by plant canopies tends to reduce multiple scattering.

\section{a. MISR - MODIS differences in aerosol optical depth}

To evaluate the contribution of the aerosol removal to the observed meridional trend, zonal means of the aerosol optical depth (AOD) values were calculated for both the winter and summer seasons. The zonal means are derived from the accumulation of the MODIS and MISR values (using AODs retrieved in the green bands of each instruments) estimated over every $0.2^{\circ}$ bins where daily coincident and valid Terra MODIS and MISR retrievals are available and positive. This spatial resolution was selected considering the spatial resolutions of the original MODIS (from MOD04) and MISR AOD products, which are close to 10 and $17.6 \mathrm{~km}$, respectively. We proceeded with the original MODIS AOD product given that its spatial resolution is much closer to that of the MISR AOD product. It should, however, be noted that the MOD09 surface reflectance values used to generate the MODIS albedo products are obtained with an atmospheric procedure (identified as MOD09) that is independent from the MOD04 AOD retrieval. The retrieval algorithms used in MOD04 AOD and MOD09 AOD are very similar regarding the physical processes they implement; for example, both capitalize on the spectral correlation of the red, blue, and shortwave infrared bands. While MOD04 AOD algorithm uses the $0.470-\mu \mathrm{m}$ band only with a prescribed aerosol model, MOD09 takes advantage of measurements available in four blue bands-that is, $0.412,0.443$, 0.470 , and $0.490 \mu \mathrm{m}$, and it has the flexibility to choose between several aerosol models. More importantly, the MOD09 AOD algorithms are operated at 1-km resolution to capture the possible high spatial variability of the aerosol load in the atmospheric correction process. Both sets of AOD products exhibit, however, very similar performances when compared with the Aerosol Robotic Network (AERONET)-derived information (e.g., Vermote and Kotchenova 2008). A consequence of the MODIS higher spatial resolution as compared to MISR is that about twice as many MODIS AODs are included in this analysis. Results obtained at the highest latitudes must be interpreted with caution owing to the decreasing number of samples; fewer than about $5 \times 10^{3}$
MISR samples are available in the winter (summer) season over regions located poleward of $40^{\circ} \mathrm{S}$ and $60^{\circ} \mathrm{N}$ $\left(70^{\circ} \mathrm{N}\right)$, respectively. Also, the bright desertic regions (e.g., the Sahara), as well as those regions significantly covered by snow, are excluded from the current analysis as the MODIS algorithm does not perform AOD retrievals in these instances. For practical reasons, the winter season accumulates AOD values from December 2004 to March 2005 and from October to November 2005, and the summer season includes the AODs from the remaining months of the year 2005. The zonal means are based on AOD values available from MODIS collection 5 (MOD04) and those generated by version 22 of the MISR processor. The MODIS AODs are quality screened and only those retrievals with MODIS aerosolestimated quality or a quality confidence (QC) flag equal to 3 are used (see Remer et al. 2009). The MISR AODs stored in the RegBestEstimateSpectralOptDepth field of the RegParamsAer grid available from the L2AS product and successful retrievals associated with AlgTypeFlag equal to 3 are considered here.

Figure 5 summarizes the results of this investigation for the summer (top panel) and winter (middle panel) seasons as well as the seasonal variations for the year 2005 (bottom panel) averaged at $1^{\circ}$ resolution, respectively. Well-defined meridional trends are observed in both seasons from both the MODIS and MISR datasets with generally larger AOD values in the intertropical regions than poleward of $30^{\circ}$. The latitudinal variations of MISR AODs appear somewhat smoother than those derived from MODIS. The MODIS values tend to exceed those from MISR except between $10^{\circ}$ and $30^{\circ} \mathrm{S}$ in the winter season and between $5^{\circ}$ and $15^{\circ} \mathrm{N}$ in the summer season, respectively, where the differences between both datasets reach maxima of 0.05 . The most noticeable temporally consistent large-scale discrepancy (differences on the order of 0.1 ) between both datasets is found in the latitude band between approximately $25^{\circ}$ and $40^{\circ} \mathrm{N}$ and at the extreme latitudes considered here in the Southern Hemisphere (with a much reduced number of AOD samples as compared to lower-latitude regions). Given that the large desertic regions are excluded from this analysis, the main discrepancy in the Northern Hemisphere concerns mainly the aerosol load estimated over India and China. Other noticeable differences such as those occurring in the Southern Hemisphere around $10^{\circ}$ in the summer season as well as between $25^{\circ}$ and $35^{\circ}$ in the winter season are probably associated with significant contributions from seasonal fire events. The MISR - MODIS differences are rather large (MODIS AODs are about twice as large as those reported by MISR) over regions south of $35^{\circ} \mathrm{S}$, but the former in fact concerns a limited-area extent as compared 

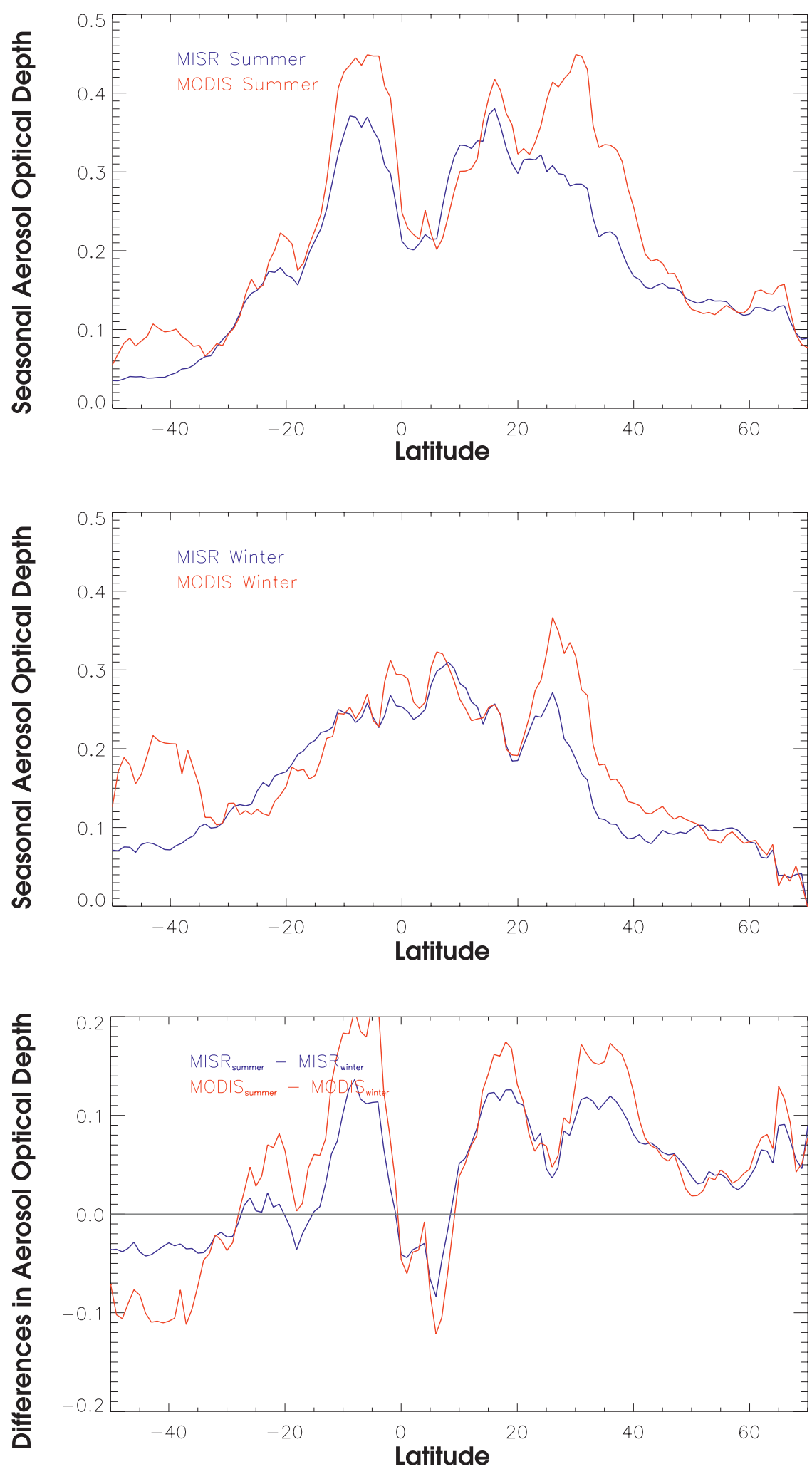

FIG. 5. Zonal means of the AOD values in (top) northern summer and (middle) winter estimated for the year 2005 from MISR (blue) and MODIS (red). (bottom) The seasonal variations (northern summer - northern winter) in AOD from both sensors are displayed. Plots are at $1^{\circ}$ latitudinal resolution. 
to lower-latitude bands. The vast majority of the largescale MODIS versus MISR AOD differences discussed here are reasonably well understood and have been documented in many instances in the literature (see, e.g., Kim and Ramanathan 2008; Mishchenko et al. 2009). Kahn et al. (2009) provide an extensive summary of known limitations and relative performance of retrieval algorithms from both instruments.

The regional-scale discrepancies, that is, those occurring in limited latitude bands, in aerosol load translate into limited surface albedo differences and may explain some of the observed variations superimposed on the albedo meridional trends discussed in section $2 \mathrm{~b}$. For instance, those regions where MODIS AODs largely exceed MISR AODS are associated with enhanced positive differences in MISR - MODIS surface albedo (see middle panel in Fig. 2). Some level of correlation between the two perturbations exists in all three broadband domains, but it is more apparent in the near-infrared domain because of the absence of the smile effect contaminating the albedo differences in the visible domain.

The seasonal variations in AODs derived from MISR and MODIS, respectively (bottom panel on Fig. 5), are in remarkably good agreement regarding the phase, but MODIS AODs are consistently skewed to high values as compared to MISR. Both datasets report well-marked seasonal variations at the global scale with the occurrence of larger AOD values during the summer period in the Northern Hemisphere. The signatures of the seasonal fire activities in the intertropical regions are also well detected. It is noteworthy that the seasonal variations derived from MISR and MODIS AOD datasets agree very well in the wide latitude band extending from $40^{\circ}$ to $70^{\circ} \mathrm{N}$, where the seasonal statistics are based on a rather large number of samples.

This large-scale analysis of the MODIS and MISR AODs does not clearly reveal discernible consistent meridional trends mirroring the one observed at global scale in the visible broadband albedo.

\section{b. Representation of surface anisotropy}

The observed smile effect suggests that MODIS whitesky albedo values are biased low relative to the MISR analogous product, and this is particularly noticeable at high latitudes - that is, under the occurrence of high sun zenith angle conditions. The latter are conditions where the derivative of DHR or black-sky albedo against the sun zenith angle is getting steep, that is, the $\operatorname{DHR}\left(\mu_{0}\right)$ increases significantly with the sun zenith angle. As expressed by Eq. (3) in Taberner et al. (2010), the white-sky surface albedo is estimated as the product of an amplitude component, the $\rho_{0}$ factor, and an angular component, the $\alpha$ coefficient, describing the anisotropy of the surface. Since $\alpha$ is the hemispherical integral of the angular contribution of $\operatorname{DHR}\left(\mu_{0}\right)$ with respect to all possible $\mu_{0}$, an underestimation of surface anisotropy, that is, too weak a deviation from isotropic-Lambertian conditions, translates into relatively lower $\alpha$ coefficients and hence lower white-sky albedo values. Conversely, the occurrence of larger $\alpha$ coefficients that is due to an overestimation of surface anisotropy yields comparatively larger white-sky albedo values.

Discrepancies in the estimation of the $\alpha$ coefficient are quite possible given the different angular sampling associated with the MODIS (across-track) and MISR (along-track) instruments and especially with respect to the viewing azimuthal conditions where both sensors are almost perpendicular to each other. At mid-high latitudes in the Northern Hemisphere, for instance, MODIS samples are preferably near the principal plane (the plane containing the sun and the local normal) by contrast to MISR whose angular samples are distributed relatively closer to the orthogonal plane (see, e.g., Jin et al. 2002; Lucht 1998). Such limited sampling capabilities may thus yield biased estimates of the $\alpha$ coefficients and therefore of the white-sky albedos depending on the latitude and the time of the year. It would be expected that the amplitude of such biases would be modulated by the architectural and scattering properties of the prevailing vegetation cover that controls the surface anisotropy patterns. Using the AERONET-based Surface Reflectance Validation Network (Lyapustin et al. 2006), Wang et al. (2010) have demonstrated that the Lambertian approximation implemented in the MODIS atmospheric correction algorithm weakens the retrieved surface anisotropy over vegetated surfaces. This approximation translates into an underestimation of surface albedos that increases with the solar zenith angle.

The possibility of a systematic underestimation of surface anisotropy by MODIS at the global scale can be investigated by assessing the MISR - MODIS seasonal trend differences on the basis of various albedo quantities derived from MISR under different angular assumptions including 1) the MISR operational land BHR product that, by definition, incorporates a dependence with the sun zenith angle; 2) the MISR white-sky albedo $\left(\mathrm{BHR}_{\text {iso }}\right)$, which accounts for anisotropy after integration over the hemisphere (the quantity used so far in the comparison and defined in section 2.1 in Taberner et al. 2010); and 3) the virtual Lambertian MISR white-sky albedo derived assuming purely isotropic or Lambertian surface conditions $[\alpha$ is forced equal to unity in Eq. (3) in Taberner et al. (2010)]. The MISR operational land BHR product is used here to highlight the influence of a remaining sun zenith angle dependence that should enhance the anisotropy effects. This product is, indeed, 
closer to a $\operatorname{DHR}\left(\mu_{0}\right)$ or black-sky quantity than a whitesky albedo especially under clear-sky conditions where direct sun illumination dominates the downwelling radiance field.

Figure 6 shows the results of the seasonal changes calculated successively from these three types of MISR surface albedo as compared to MODIS white-sky products. It appears that the angular effects affecting the MISR products are dampened when inspecting Fig. 6 sequentially from the top (based on the operational MISR land BHR) to the bottom (based on Lambertian MISR white-sky albedo) panels. These modifications in the accounting of the angular and especially the sun zenith effects translate into an anticlockwise rotation, centered around the equatorial regions, of the seasonal changes witnessed by the MISR-derived products. As a matter of fact, the overall agreement between the MODIS- and MISR-based results increases over both hemispheres when the anisotropy effects are artificially weakened by forcing the surfaces to behave as Lambertian. Similar conclusions are reached when duplicating this exercise using the near-infrared domain datasets. One may logically expect that amplifying the anisotropy effects on the MODIS products would similarly yield an improved agreement between the MODIS and MISR white-sky albedo products.

The residuals of the seasonal changes calculated from MODIS and MISR white-sky products, that is, the absolute differences between the blue and red curves from the middle and bottom panels in Fig. 6, are displayed in Fig. 7. As can be expected from previous results, the residuals exhibit a well-defined and consistent meridional trend with latitude. This trend is almost linear and ranges from approximately -0.02 at $40^{\circ} \mathrm{S}$ to +0.03 at $60^{\circ} \mathrm{N}$, crossing the zero line at about $5^{\circ} \mathrm{N}$. It must be recalled that the impact of the bias or offset apparent in the top panel of Fig. 2 is cancelled when accounting for the seasonal differences in this residual. A flawless agreement between both datasets in representing the seasonal changes would thus yield unbiased residual values close to zero.

Results shown in the middle panel of Fig. 7, corresponding to the residual of the seasonal changes when using the MISR Lambertian white-sky albedo, are characterized by regional-scale variations superimposed on a slight linear meridional trend with a weaker slope (approximately from -0.01 to +0.01 between $40^{\circ} \mathrm{S}$ and $50^{\circ} \mathrm{N}$ ) than observed on the top panel. Interestingly, the regional-scale variations exposed by this residual quantity appear to be in phase with the MISR - MODIS aerosol optical depth differences of the zonal means calculated for the winter and summer seasons, respectively (shown in the bottom panel); relatively low (high) and eventually negative values in latitude bands $\left[25^{\circ}-35^{\circ} \mathrm{N}\right]$ and $\left[0^{\circ}-10^{\circ} \mathrm{S}\right]\left(\left[5^{\circ}-15^{\circ} \mathrm{N}\right]\right.$ and $\left.\left[15^{\circ}-25^{\circ} \mathrm{S}\right]\right)$ are indeed apparent in both panels.

The AOD differences between the MODIS and MISR sensors are consistent with the residual differences in surface albedo in the visible band in the sense that an excess in AOD values is associated with lower surface albedos. The precise assessment of the impact of AOD discrepancies on surface albedo values is a rather heavy task to achieve with actual data, for example, ingesting MISR AOD values to retrieve MODIS surface albedos as well as eliminating the effects of the intersensor spectral biases that may exist on the top of atmosphere measurements, which affect the surface and aerosol retrievals. This impact depends on a number of properties of the atmospheric and surface layers as well as the illumination conditions. Tables 1 and 2 summarize results from the 6S (Kotchenova et al. 2006; Kotchenova and Vermote 2007) radiation transfer model simulations pertaining to the broadband visible and near-infrared spectral domains, respectively. Both tables give the calculated differences between the true and the retrieved surface albedos, assuming AOD values biased by $25 \%$ over the true AOD value. As expected, the largest albedo differences occur for the darkest surface and highest AOD conditions considered here, and these differences increase with the sun zenith angle due to the enhanced atmospheric path length. The differences may be positive or negative around the "neutral" albedo point where the increase (due to larger AODs) in the atmospheric radiance is roughly compensated by an equivalent decrease from the atmospheric transmittance contribution, which encapsulates the surface albedo signal. These differences are also 2-3 times smaller in the near-infrared than in the visible domain because of the decreasing efficiency of the aerosol-scattering processes with increasing wavelengths. Given that regional-scale differences in MISR and MODIS AODs may exceed the conditions used in the present simulations, that is, $25 \%$ relative bias, it is possible that the MISR - MODIS differences in AODs contribute to some of the observed albedo differences at regional scale. These results suggest, however, that the smile effect observed in the visible domain cannot be explained by the MISR - MODIS zonal differences in AODs.

It must be kept in mind that strictly speaking the potential impact on surface products would require investigating the differences in the downwelling radiance fields, given that different aerosol models may yield similar downward radiances at ground level due to the nonuniqueness of the solution to the inverse problem; that is, variations in AOD may be partly compensated by variations in other aerosol model parameters. It remains, however, very unlikely that differences in 

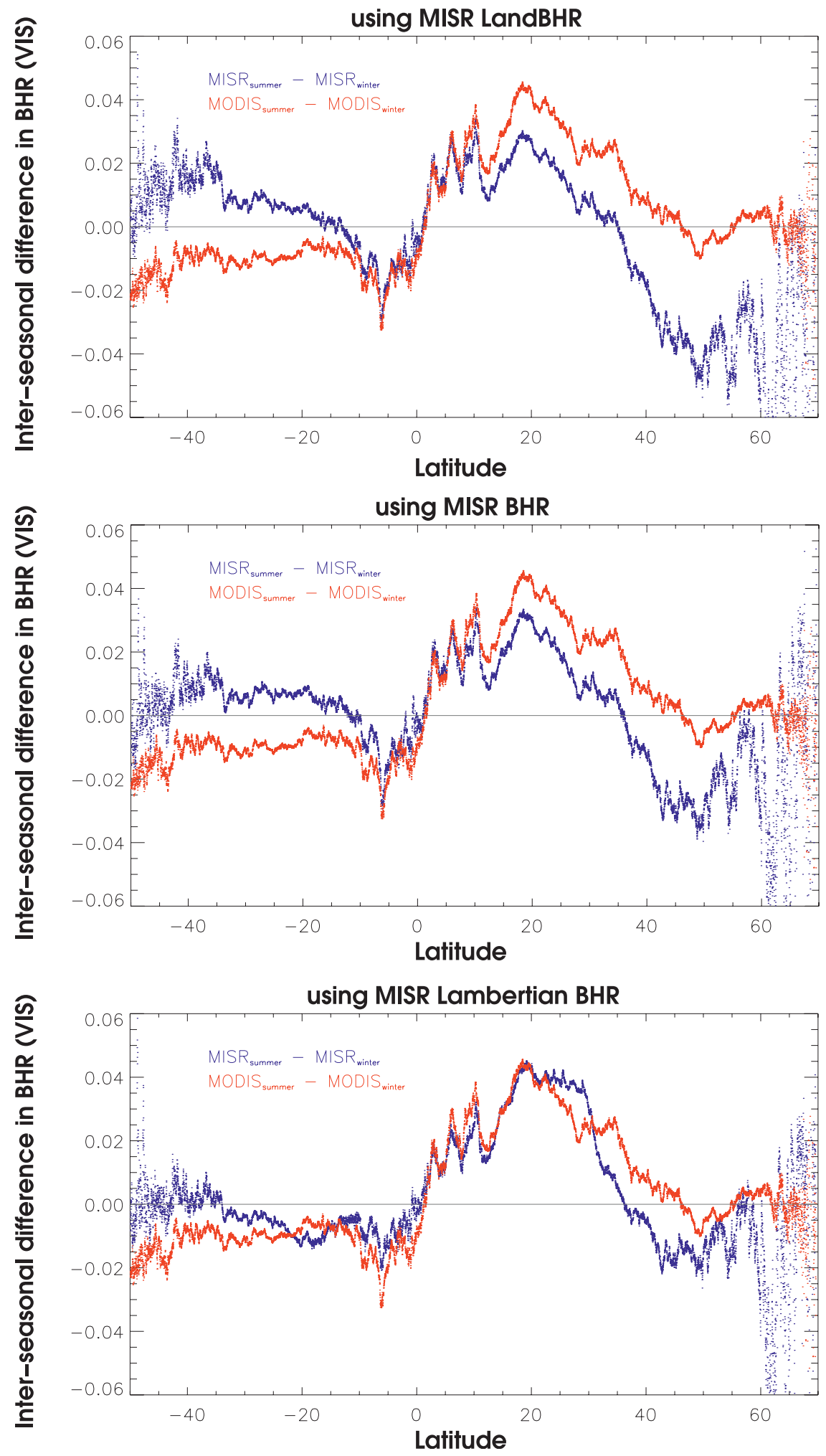

FIG. 6. Seasonal variations (northern summer - northern winter) estimated for the year 2005 from the MISR (blue) and MODIS (red) zonal-averaged surface albedo values. (top) The MISR land BHR operational products, (middle) the MISR white-sky albedo, and (bottom) the Lambertian MISR white-sky albedo are shown. 
using MISR BHR

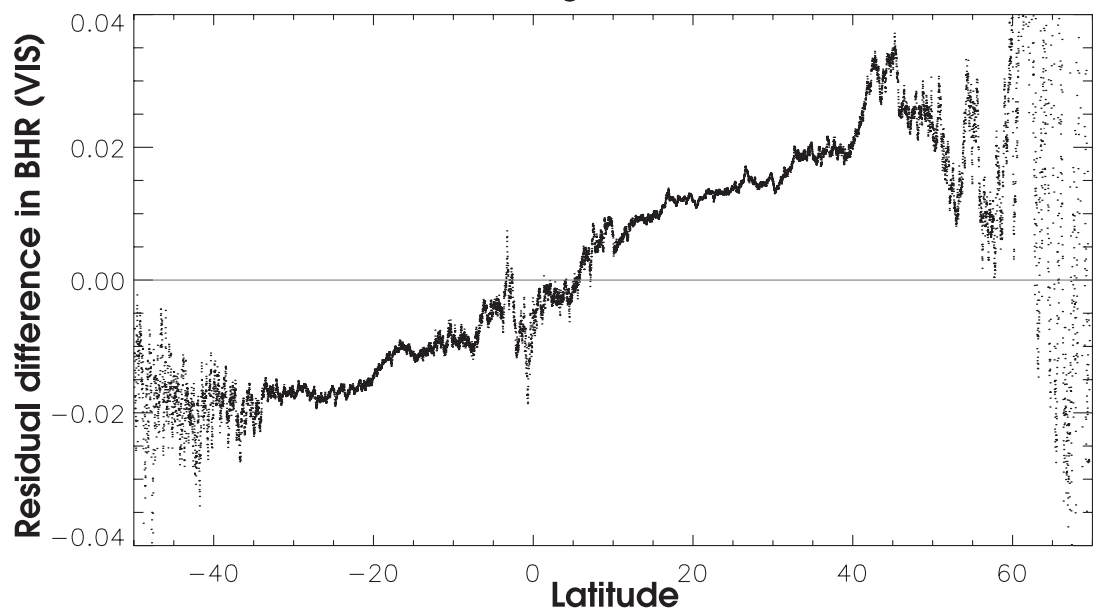

using MISR Lambertian BHR
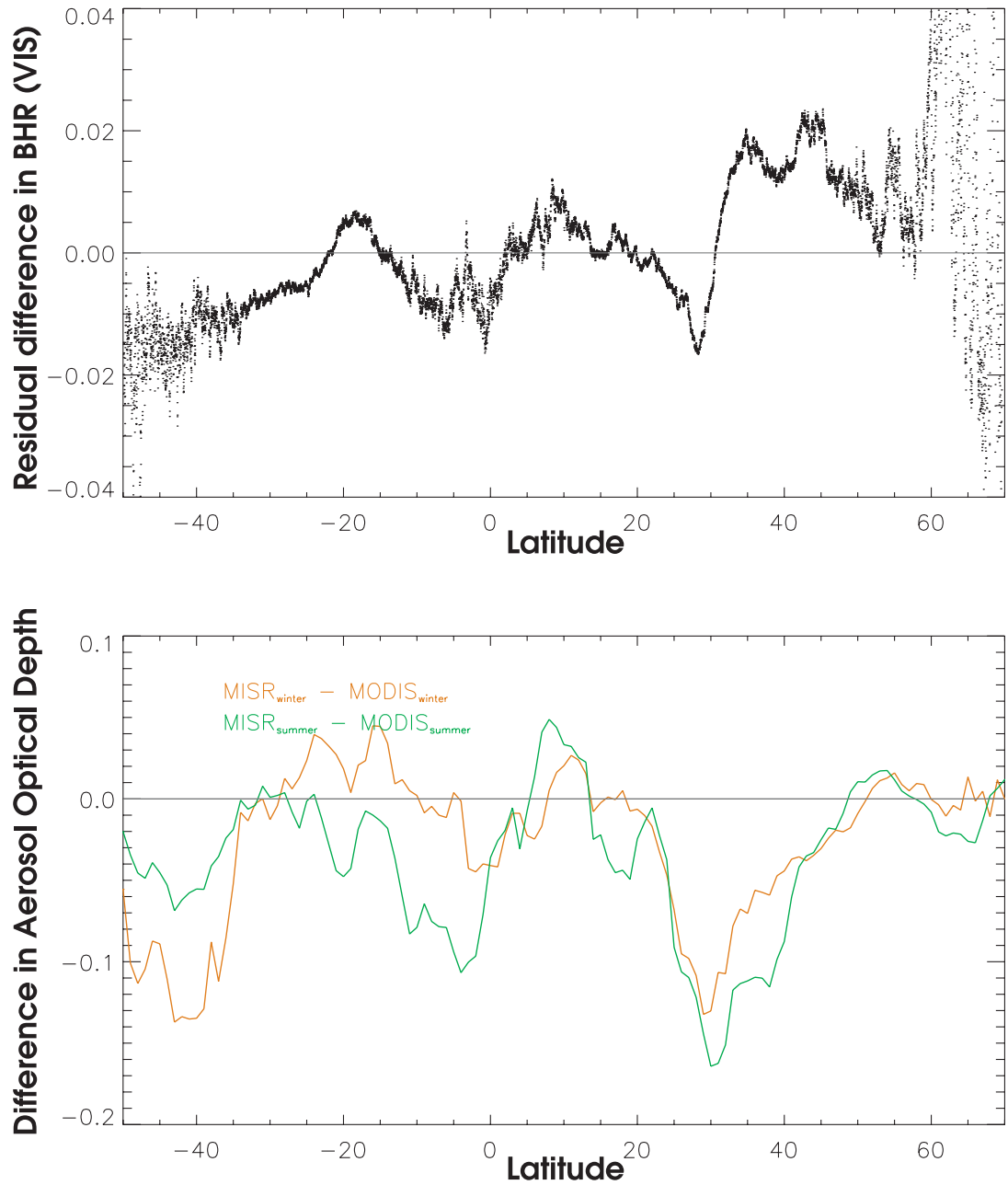

FIG. 7. Residual of the seasonal variations (northern summer - northern winter) estimated for the year 2005 from the MISR and MODIS zonal-averaged surface albedo values. (top) The MISR white-sky albedo and (middle) the Lambertian MISR white-sky albedo are shown. (bottom) MISR - MODIS AOD absolute differences of the zonal means calculated for the winter (in brown) and summer (in green) seasons are shown. 
TABLE 1. Simulated differences between the true and retrieved broadband visible surface albedo values at different sun zenith angles and with various AOD conditions. The albedo differences are due to a $25 \%$ positive bias of the true AOD. Negative values are in bold.

\begin{tabular}{|c|c|c|c|c|}
\hline \multirow{2}{*}{$\begin{array}{c}\mu_{0}\left(\cos \mu_{0}\right) \\
\mathrm{BHR}_{\text {true }}^{\mathrm{a}}\end{array}$} & $0^{\circ}(1.0)$ & $30^{\circ}(0.866)$ & $60^{\circ}(0.50)$ & $70^{\circ}(0.342)$ \\
\hline & \multicolumn{4}{|c|}{$\Delta\left(\mathrm{BHR}_{\text {retrieved }}^{\mathrm{b}}-\mathrm{BHR}_{\text {true }}\right)$} \\
\hline $\mathrm{AOD}_{\text {true }}^{\mathrm{a}} / \mathrm{AOD}_{\text {biased }}^{\mathrm{c}}$ & \multicolumn{4}{|c|}{$0.1 / 0.125$} \\
\hline 0.05 & -0.0012 & -0.0006 & -0.0016 & -0.0028 \\
\hline 0.1 & -0.0001 & +0.0005 & +0.0000 & -0.0007 \\
\hline 0.2 & +0.0017 & +0.0025 & +0.0030 & +0.0030 \\
\hline $\mathrm{AOD}_{\text {true }} / \mathrm{AOD}_{\text {biased }}$ & \multicolumn{4}{|c|}{$0.2 / 0.25$} \\
\hline 0.05 & -0.0030 & -0.0023 & -0.0045 & -0.0067 \\
\hline 0.1 & -0.0012 & -0.0003 & -0.0017 & $-\mathbf{0 . 0 0 3 2}$ \\
\hline 0.2 & +0.0199 & +0.0032 & +0.0034 & +0.0030 \\
\hline $\mathrm{AOD}_{\text {true }} / \mathrm{AOD}_{\text {biased }}$ & \multicolumn{4}{|c|}{$0.4 / 0.5$} \\
\hline 0.05 & -0.0067 & -0.0060 & -0.0114 & -0.0149 \\
\hline 0.1 & -0.0033 & -0.0023 & -0.0062 & -0.0089 \\
\hline 0.2 & +0.0028 & +0.0044 & +0.0034 & +0.0024 \\
\hline
\end{tabular}

a True values of the BHR and AOD.

${ }^{\mathrm{b}}$ BHR value retrieved using the biased AOD value.

${ }^{c}$ AOD value biased by $25 \%$ over the true value.

aerosol attributes specified in the MODIS and MISR AOD algorithms may significantly help understanding the observed large-scale smile effect in surface albedos in the visible domain.

\section{Conclusions}

Global-scale statistics have been analyzed to assess the biases, trends, and differences between the operational MODIS white-sky broadband surface albedos and the equivalent products generated on the basis of the MISR BRF model surface parameters. The methodology and the comparison strategy proposed in Taberner et al. (2010) have been shown to deliver very encouraging results despite the many differences that exist in the suite of algorithms applied to retrieve these surface quantities from each instrument independently. The high level of correlation between the MODIS and MISR albedos has been confirmed by the large-scale statistics. However, an in-depth analysis of the MISR - MODIS surface albedo absolute differences of the zonal means calculated for the winter and summer seasons reveals a consistent meridional trend featuring a smile effect, especially discernible in the visible domain. This smile effect appears on top of a systematic MISR - MODIS positive bias or offset in the range $0.01-0.03$ depending on the spectral domain.

The seasonal changes in surface albedo estimated from MISR and MODIS datasets in the near-infrared domain have been shown to be consistent between themselves (considering the uncertainties associated with the limited spectral sampling of MISR), especially over the
TABLE 2. Simulated differences between the true and retrieved broadband near-infrared surface albedo values at different sun zenith angles and with various AOD conditions. The albedo differences are due to a $25 \%$ positive bias of the true AOD. Negative values are in bold.

\begin{tabular}{|c|c|c|c|c|}
\hline \multirow{2}{*}{$\begin{array}{c}\mu_{0}\left(\cos \mu_{0}\right) \\
\mathrm{BHR}_{\text {true }}^{\mathrm{a}}\end{array}$} & $0^{\circ}(1.0)$ & $30^{\circ}(0.866)$ & $60^{\circ}(0.50)$ & $70^{\circ}(0.342)$ \\
\hline & \multicolumn{4}{|c|}{$\Delta\left(\mathrm{BHR}_{\text {retrieved }}^{\mathrm{b}}-\mathrm{BHR}_{\text {true }}\right)$} \\
\hline $\mathrm{AOD}_{\text {true }}^{\mathrm{a}} / \mathrm{AOD}_{\text {biased }}^{\mathrm{c}}$ & \multicolumn{4}{|c|}{$0.1 / 0.125$} \\
\hline 0.1 & -0.0007 & -0.0004 & -0.0007 & -0.0013 \\
\hline 0.2 & -0.0004 & -0.0001 & -0.0002 & -0.0005 \\
\hline 0.4 & +0.0001 & +0.0005 & +0.0009 & +0.0011 \\
\hline $\mathrm{AOD}_{\text {true }} / \mathrm{AOD}_{\text {biased }}$ & \multicolumn{4}{|c|}{$0.2 / 0.25$} \\
\hline 0.1 & -0.0013 & -0.0007 & -0.0014 & -0.0024 \\
\hline 0.2 & -0.0005 & +0.0001 & +0.0000 & -0.0005 \\
\hline 0.4 & +0.0010 & +0.0017 & +0.0026 & +0.0032 \\
\hline $\mathrm{AOD}_{\text {true }} / \mathrm{AOD}_{\text {biased }}$ & \multicolumn{4}{|c|}{$0.4 / 0.5$} \\
\hline 0.1 & -0.0023 & -0.0016 & -0.0031 & -0.0053 \\
\hline 0.2 & -0.0005 & +0.0004 & -0.0000 & -0.0011 \\
\hline 0.4 & +0.0029 & +0.0042 & +0.0058 & +0.0067 \\
\hline
\end{tabular}

a True values of the BHR and AOD.

${ }^{\mathrm{b}}$ BHR value retrieved using the biased AOD value.

${ }^{c}$ AOD value biased by $25 \%$ over the true value.

Northern Hemisphere, as well as with expectations based on broad features of vegetation phenology. By contrast, noticeable deviations from this situation have been obtained from the analysis of the visible albedo products.

It has been shown, in particular, that strong seasonal changes can be observed in the MISR albedo products: a decrease in albedo is seen with the onset and progression of the growing season that can be explained by increased absorption by the green phytoelements of the vegetation cover and an increase in albedo with the onset of senescence and harvest arising from a reduction in absorption. In comparison, the MODIS products generate much weaker seasonal changes.

This discrepancy in meridional trend has consequences on downstream surface-oriented applications, which use the surface BRFs and albedo products as inputs to inverse algorithms to retrieve land surface properties. This has motivated an in-depth analysis of the differences in the retrieved aerosol load as well as in the accounting of surface angular effects by both MODIS and MISR. The main conclusions of this latter investigation can be summarized as follows:

- the intersensor differences in retrieved aerosol optical depths could explain some of the regional-scale differences observed in surface albedo but are highly unlikely to cause the observed, large-scale meridional trend in visible surface albedos; and

- the most significant part of the meridional trend in the visible albedo is compatible with an underestimation (overestimation) of the surface anisotropy by MODIS (MISR) as a possible consequence of their different 
angular-sampling strategies and/or approximations in the atmospheric correction processes.

These conclusions are drawn on the basis of the following facts: 1) the seasonal variations in the near-infrared albedos from both MODIS and MISR are consistent with expectations based on broad patterns of large-scale vegetation phenology (middle panel in Fig. 3);2) the agreement between MISR and MODIS visible albedo significantly increases when anisotropy effects are artificially weakened in MISR albedo products (bottom panel in Fig. 6); and 3) the residual differences between the MODIS visible albedo products and that of MISR, obtained when forcing the surfaces to behave as Lambertian, are approximately varying in phase along the latitude with the differences in MISR and MODIS AOD products (middle and bottom panels in Fig. 7).

The suggestion of an underestimation of anisotropy by MODIS is corroborated by results obtained in a different context at local scale, namely, the comparison of the dependence of MODIS $\operatorname{DHR}\left(\mu_{0}\right)$ black-sky albedo products with sun zenith angle against in situ measurements. It has indeed been shown (e.g., Yang et al. 2008; Liu et al. 2009) that the MODIS products tend to consistently underestimate the albedo measured in situ at sun zenith angles larger than $55^{\circ}$. The range of the underestimation found in these studies is comparable with that reported in the present study. The increasing contribution from the diffuse downwelling radiance field adds even more uncertainties on the comparison results and enhances as well the contribution due to the coupling between aerosol load and type and the surface albedo retrieval (Pinty et al. 2005; Román et al. 2010).

The reasons for an underestimation of angular effects by MODIS and/or an overestimation by MISR are manifold and may involve coupled contributions from different sources such as 1) the biased azimuthal MODIS and MISR sampling of the scattered radiance field at high latitudes that may affect the extrapolation of the BRF values at sun angles that have not been measured and 2) the performance of the parametric models to extrapolate the local BRF field estimated locally in the angular domain to the full hemisphere. As mentioned previously, the impact of these factors may be augmented by the coupling of the surface and aerosol-scattering properties and the Lambertian approximation in the MODIS atmospheric correction process (see, e.g., Wang et al. 2010).

Further detailed and careful investigations are needed to understand the origin of this meridional trend, which has been uncovered through an analysis of large-scale statistics and, if possible, to account and correct for it. The series of arguments discussed in the current paper supports the hypothesis of a slight underestimation (overestimation) of surface anisotropy notably affecting the MODIS (MISR) visible albedo products and contribute to drawing a coherent picture of complementary results published elsewhere.

Acknowledgments. This research was performed in the Global Environment Monitoring unit of the Institute for Environment and Sustainability at the Joint Research Centre, an institution of the European Commission. The authors thank the providers of the remote sensing datasets needed to perform this research. The MISR products were obtained from the NASA Langley Research Center Atmospheric Sciences Data Center. The MODIS products were obtained from the National Snow and Ice Data Center and the NASA Land Processes Distributed Active Archive Centers.

\section{REFERENCES}

Avissar, R., and M. M. Verstraete, 1990: The representation of continental surface processes in mesoscale atmospheric models. Rev. Geophys., 28, 35-52.

Bartholomé, E., and A. Belward, 2005: GLC2000: A new approach to global land cover mapping from earth observation data. Int. J. Remote Sens., 26, 1959-1977.

Betts, A. K., P. D. Falloon, K. K. Goldewijk, and N. Ramankutty, 2007: Biogeophysical effects of land use on climate: Model simulations of radiative forcing and large-scale temperature changes. Agric. For. Meteor., 142, 216-233.

Dickinson, R. E., 1983: Land surface processes and climate-Surface albedos and energy balance. Advances in Geophysics, Vol. 25, Academic Press, 305-353.

_ L. Lhou, Y. Tian, Q. Liu, T. Lavergne, B. Pinty, C. B. Schaaf, and Y. Knyazikhin, 2008: A three-dimensional analytic model for the scattering of a spherical bush. J. Geophys. Res., 113, D20113, doi:10.1029/2007JD009564.

Gao, F., C. B. Schaaf, A. H. Strahler, A. Roesch, W. Lucht, and R. E. Dickinson, 2005: Climate modeling grid products and the variability of albedo for major global vegetation types. J. Geophys. Res., 110, D01104, doi:10.1029/2004JD005190.

Jin, Y., C. B. Schaaf, X. Li, A. H. Strahler, C. J. Bruegge, and J. V. Martonchik, 2002: Improving MODIS surface BRDF/ albedo retrieval with MISR multiangle observations. IEEE Trans. Geosci. Remote Sens., 40, 1593-1602.

Kahn, R. A., and Coauthors, 2009: MISR aerosol product attributes, and statistical comparisons with MODIS. IEEE Trans. Geosci. Remote Sens., 47, 4095-4114.

Kim, D., and V. Ramanathan, 2008: Solar radiation budget and radiative forcing due to aerosols and clouds. J. Geophys. Res., 113, D02203, doi:10.1029/2007JD008434.

Kondratyev, K., 1972: Radiation Processes in the Atmosphere. World Meteorological Organization Publishing, 214 pp.

Kotchenova, S. Y., and E. F. Vermote, 2007: Validation of a vector version of the $6 \mathrm{~S}$ radiative transfer code for atmospheric correction of satellite data. Part II: Homogeneous Lambertian and anisotropic surfaces. Appl. Opt., 46, 4455-4464.

,,- R. Matarrese, and F. J. Klemm, 2006: Validation of a vector version of the $6 \mathrm{~S}$ radiative transfer code for atmospheric correction of satellite data. Part I: Path radiance. Appl. Opt., 45, 6762-6774. 
Lewis, P., and M. Barnsley, 1994: Influence of the sky radiance distribution on various formulations of the earth surface albedo. Proc. Sixth ISPRS International Symp. on Physical Measurements and Signatures in Remote Sensing, Val d'Isère, France, CNES, 707-715.

Liu, J., and Coauthors, 2009: Validation of Moderate Resolution Imaging Spectroradiometer (MODIS) albedo retrieval algorithm: Dependence of albedo on solar zenith angle. J. Geophys. Res., 114, D01106, doi:10.1029/2008JD009969.

Liu, Q., L. Gu, R. E. Dickinson, Y. Tian, L. Zhou, and W. M. Post, 2008: Assimilation of satellite reflectance data into a dynamical leaf model to infer seasonnally varying leaf areas for climate and carbon models. J. Geophys. Res., 113, D19113, doi:10.1029/2007JD009645

Lucht, W., 1998: Expected retrieval accuracies of bidirectional reflectance and albedo from EOS-MODIS and MISR angular sampling. J. Geophys. Res., 103, 8763-8778.

Lyapustin, A., Y. Wang, J. Martonchik, J. Privette, B. Holben, I. Slutsker, A. Sinyuk, and A. Smirnov, 2006: Local analysis of MISR surface BRF and albedo over GSFC and Mongu AERONET sites. IEEE Trans. Geosci. Remote Sens., 44, 1707-1718.

—, and Coauthors, 2007: Analysis of MODIS-MISR calibration differences using surface albedo around AERONET sites and cloud reflectance. Remote Sens. Environ., 107, 12-21.

Mishchenko, M. M., I. V. Geogdzhayev, L. Liu, A. A. Lacis, B. Cairns, and L. D. Travis, 2009: Toward unified satellite climatology of aerosol properties: What do fully compatible MODIS and MISR aerosol pixels tell us? J. Quant. Spectrosc. Radiat. Transf., 110, 402-408.

Moody, E. G., M. D. King, C. B. Schaaf, and S. Platnick, 2008: MODIS-derived spatially complete surface albedo products: Spatial and temporal pixel distribution and zonal averages. J. Appl. Meteor. Climatol., 47, 2879-2894.

Pinty, B., M. M. Verstraete, N. Gobron, F. Roveda, and Y. Govaerts, 2000: Do man-made fires affect earth's surface reflectance at continental scales? Eos, Trans. Amer. Geophys. Union, 81, 388-389.

— surface albedo. J. Atmos. Sci., 62, 2580-2591.

—, T. Lavergne, R. E. Dickinson, J.-L. Widlowski, N. Gobron, and M. M. Verstraete, 2006: Simplifying the interaction of land surfaces with radiation for relating remote sensing products to climate models. J. Geophys. Res., 111, D02116, doi:10.1029/ 2005JD005952.
— , and Coauthors, 2007: Retrieving surface parameters for climate models from MODIS and MISR albedo products. J. Geophys. Res., 112, D01102, doi:10.1029/2005JD007008.

— and Coauthors, 2008: Partitioning the solar radiant fluxes in forest canopies in the presence of snow. J. Geophys. Res., 113, D04104, doi:10.1029/2007JD009096.

—, T. Lavergne, J.-L. Widlowski, N. Gobron, and M. M. Verstraete, 2009: On the need to observe vegetation canopies in the near infrared to estimate visible light absorption. Remote Sens. Environ., 113, 10-23.

Remer, L. A., Y. J. Kaufman, D. Tanré, R. C. Levy, and S. Mattoo, cited 2009: Algorithm for remote sensing of tropospheric aerosol from MODIS: Collection 005, Revision 2. [Available online at http://modis-atmos.gsfc.nasa.gov/MOD04_L2/index. html.]

Román, M. O., and Coauthors, 2010: Assessing the coupling between surface albedo derived from MODIS and the fraction of diffuse skylight over spatially-characterized landscapes. $R e$ mote Sens. Environ., 114, 738-760.

Sellers, P. J., and Coauthors, 1997: Modeling the exchanges of energy, water, and carbon between continents and the atmosphere. Science, 275, 502-509.

Taberner, M., B. Pinty, Y. Govaerts, S. Liang, M. M. Verstraete, N. Gobron, and J.-L. Widlowski, 2010: Comparison of MISR and MODIS land surface albedos: Methodology. J. Geophys. Res., 115, D05101, doi:10.1029/2009JD012665.

Vermote, E., and S. Kotchenova, 2008: Atmospheric correction for the monitoring of land surfaces. J. Geophys. Res., 113, D23S90, doi:10.1029/2007JD009662.

Viterbo, P., and A. K. Betts, 1999: Impact on ECMWF forecasts of changes to the albedo of the boreal forests in the presence of snow. J. Geophys. Res., 104, 27 803-27 810.

Wang, Y., A. Lyapustin, J. L. Privette, R. B. Cook, S. K. SanthanaVannan, E. F. Vermote, and C. L. Schaaf, 2010: Assessment of biases in MODIS surface reflectance due to lambertian approximation. Remote Sens. Environ., 114, 2791-2801.

Yang, F. L., K. Mitchell, Y.-T. Hou, Y. Dai, X. Zeng, Z. Wang, and X.-Z. Liang, 2008: Dependence of land surface albedo on solar zenith angle: Observations and model parameterizations. J. Appl. Meteor. Climatol., 47, 2963-2982.

Zhang, X., M. A. Friedl, and C. B. Schaaf, 2006: Global vegetation phenology from Moderate Resolution Imaging Spectroradiometer (MODIS): Evaluation of global patterns and comparison with in situ measurements. J. Geophys. Res., 111, G04017, doi:10.1029/2006JG000217. 